\title{
Adult Beginner Instrumentalists' Practice, Self-Regulation, and Self-Efficacy: A Pilot Study
}

\author{
Laura Ritchie $^{1}$, Phil Kearney ${ }^{1}$ \\ ${ }^{1}$ Department of Music, ${ }^{2}$ Institute of Sport, University of Chichester, Chichester, UK \\ Correspondence: Laura Ritchie, Department of Music, University of Chichester, Chichester, West Sussex, England, \\ PO19 6PE, UK.
}

Received: February 5, 2018

Accepted: March 11, 2018

Online Published: March 24, 2018

doi:10.11114/jets.v6i5.2978

URL: https://doi.org/10.11114/jets.v6i5.2978

\begin{abstract}
The self-regulation of practice behaviour has repeatedly been shown to distinguish between novice and expert performers, however interventions designed to encourage self-regulation by novice musicians have shown limited effectiveness. Guided by successful research in sporting contexts, the present study investigated the behaviours of beginner (novice) adult musicians' self-regulated learning, self-efficacy for learning, and practice. Participants undertook a semester of music lessons learning string instruments. Half of the group completed a self-regulation worksheet alongside practicing whereas the others listened to various pieces of music and were not instructed to implement any specific structure to their practice outside the lesson. The results showed that although the intervention was successful in promoting self-regulatory behaviours, the worksheet element had no impact on self-efficacy for learning and was not recognised by participants as directly influencing their learning. Future research should consider the directed use of the worksheet, and other practice aids in interventions and the research designs used to evaluate the effectiveness of such behaviours.
\end{abstract}

Keywords: strategic practice, metacognition, music learning, self-efficacy, self-regulation, adult, instrumentalist

\section{Introduction}

Given the limited contact time that most music students have with their teachers (Davidson \& Jordan, 2007), the promotion of effective practice is a critical task for the music teacher (Jørgensen, 2002). Learning and especially approaching new situations involves a host of mental and physical processes including aspects of cognition, metacognition, action, and personal beliefs and feelings. Zimmerman (2002) has defined self-regulation as "self-generated thoughts, feelings, and behaviours that are oriented to attaining goals" (p. 65). Research into self-regulation has identified processes such as goal-setting, self-instruction and help seeking that distinguish experts from sub-experts in domains such as sport, music and academic study (DiBenedetto \& Zimmerman, 2010; Kitsantas \& Zimmerman, 2002; McPherson \& Renwick, 2001; Zimmerman, 1998). These processes are proposed to be responsible for the development of expertise through elevating the quality of practice (Ericsson, Krampe, \& Tesch-Römer, 1993; Ertmer \& Newby, 1993).

Within the music domain specifically, the advantages of applying sophisticated self-regulatory strategies when practicing have been repeatedly demonstrated (Bartolme, 2009; Bonneville-Roussy \& Bouffard, 2015; Hallam, 2001; Miksza, 2012; Nielson, 2001; Rohwer \& Polk, 2006). Additionally, novice, beginner performers have been shown to lack key self-regulatory skills (Leon-Guerra, 2008; McPherson \& Renwick, 2001; Pitts, Davidson, \& McPherson, 2000). Learners also show poor self-awareness of their practice behaviours (Byo \& Cassidy, 2008; Hallam, 2001), or demonstrate a gap between knowledge and use of strategies (Christensen, 2010). Furthermore, Kostka (2002) identified conflicting reports from music teachers and students; while almost all teachers reported discussing practice strategies with their students, $67 \%$ of those same students reported that they had not discussed practice strategies with their teachers (see also Jørgensen, 2000). Thus, it appears that novice learners require additional assistance apart from the teacher's explanation in the lesson context to promote their use of self-regulation (Austin \& Berg, 2006).

Despite the convincing evidence that self-regulation enhances learning in music, there have been few intervention studies designed to enhance learners' use of self-regulatory processes. One exception is Hewitt (2011) who focused on encouraging students to self-evaluate. Two hundred and thirty-four participants aged 10-14 years were assigned to one of three groups: a control group that received music lessons only, a self-evaluation group that was asked to complete a self-evaluation form, and a self-evaluation group that was taught to self-evaluate. After the five-week 
intervention, results indicated that instruction in self-evaluation had not enhanced musical performance. It is interesting to note, however, that time spent learning about self-evaluation (and hence, not practicing music) had not negatively impacted upon students' learning. Hewitt suggested two possible explanations for the failure of the intervention: its relatively short duration, and the inaccurate self-evaluations demonstrated by the students throughout the study. That students struggled to provide accurate self-evaluations suggests that interventions attempting to enhance self-regulation should focus on alternative means of promoting self-regulation.

Whilst interventions within music are limited, a number of studies in other domains, such as sport, have investigated the effectiveness of instructing participants on how to self-regulate their practice behaviours. In contrast to Hewitt (2011), these interventions have focused on a broader range of self-regulatory strategies. For example, Zimmerman and colleagues (Cleary, Zimmerman \& Keating, 2006; Kitsantas \& Zimmerman, 1998; Zimmerman \& Kitsantas, 1996, 1997) proposed a three-stage learning strategy involving the setting of process goals, the recording of performance, and strategic self-reflection. Despite performing fewer trials within the allocated time, participants who practiced with the three-stage strategy demonstrated superior performance in a basketball shooting task (Cleary et al., 2006) or dart throwing (Kitsantas \& Zimmerman, 1998; Zimmerman \& Kitsantas, 1996, 1997) immediately after practice compared to participants who were not taught a practice strategy. Furthermore, participants who were instructed in self-regulation showed higher levels of self-efficacy relative to control participants (Zimmerman \& Kitsantas, 1996, 1997). Given these consistently successful results, the three-stage strategy advocated by Zimmerman and colleagues may provide an effective guide to self-regulation for music students.

Although self-regulation can be taught to learners of all ages, across areas of study (Dignath van Ewijk, 2011), the present study focuses on adults. In music there are very few studies exploring the nature of adults as beginner instrumentalists. As adults, the participants in this study would be able to self-report and clearly articulate their learning processes and any engagement with self-regulation.

\section{Aims}

This study aims to investigate the effects of a worksheet designed to encourage novice adult musicians to engage in Zimmerman's three stage self-regulation strategy by structuring and implementing strategies during independent practice. Based upon previous self-regulation interventions in the sport domain, and on comparisons of the practice behaviours of expert and novice musicians, we hypothesised that participants encouraged to use self-regulation with an external practice aid would demonstrate superior learning, enhanced self-efficacy for learning, and more sophisticated self-reported practice behaviours relative to those who were not instructed to undertake any specific behaviours to aid their learning. A mixed methods approach allowed for the collection of both quantitative and qualitative data in order to corroborate results (Creswell \& Plano Clark, 2007; Fitzpatrick, 2011).

\section{Quantitative and Qualitative Research Questions}

1. Do baseline measurements of self-efficacy change over the duration of the study?

2. How do these beginners use practice time?

3. How are these beginners able to self-regulate their learning?

Mixed Methods Question

1. How do the participant diaries and interviews support the numbers and level of performance achieved throughout the period of study?

\section{Method}

\subsection{Participants}

Adults who had never learned a string instrument were recruited from a university staff and student population. Twenty-two individuals were recruited to participate in the study, and were randomly assigned to groups for weekly lesson times. Ethical approval was obtained from the Institutional Research Ethics Committee. To be included in the study, applicants were required to A) have no experience with string instruments, (this was verified through the initial performance assessment) and B) agree to attend weekly lessons, engage in the recommended regular practice, and complete forms throughout the study as required.

\subsection{Procedure}

Questionnaires and baseline performance assessments were used to gather quantitative data alongside the qualitative self-reported measures with semi-structured interviews at the completion of the intervention. With a small number of participants, the questionnaires were used to gather baseline data, and to serve as a guide for a future, larger study. The individual self-reported information forms the basis of the qualitative part of the study. Participants chose to learn either the violin or the cello. Teaching 
beginner strings together is commonly practised in group teaching settings within the school system in the UK.

\subsubsection{Initial Assessment}

Participants initially completed the Self-efficacy for Musical Learning questionnaire, validated by Ritchie and Williamon (2011) and after their first introductory lesson to the instrument, participants' baseline skill level was assessed by their performance of both a one octave major scale and Twinkle Twinkle Little Star. No one was expected to be able to perform these tasks, but had someone downplayed previous experience, this performance task would have revealed them not to be a complete beginner. Participants attempted this task in a rehearsal room on their own and were video recorded. To confirm that participants were indeed unskilled and novices on these string instruments, videos were analysed by a music department staff member, who had more than 10 years experience and was not associated with the participants. Participants were scored on scales from 1 (poor) to 10 (excellent) in the categories of intonation, rhythm, and accuracy of the notes played.

\subsubsection{Music Lessons and Independent Practice}

In this study the researchers controlled for the location, teacher influence, and teaching content of the lessons. This, combined with the baseline skill level of novice learners minimised the possibility of any confounding musical influences. All participants experienced the same structured lesson plans introducing instrumental technique and listening skills as taught in weekly, one-hour group instrumental lessons. The lessons were taught by one of the researchers, whose role was to teach the lessons, and all other data was collected by the other researcher. The teacher had over 20 years experience teaching lessons and had designed curricula for individual learning as well as degree programmes at undergraduate and masters level. To control for quality of teaching across groups, a strict sequence of instruction (curricular content and instructional activities) was followed. In addition, lessons were video recorded to ensure the consistency of teaching across the groups. A research assistant, who was blind to whether they were observing the lesson of a placebo or intervention group, observed a random selection of lessons to ensure adherence to the sequence of instruction and consistency between groups.

Participants in both groups were asked to commit to practicing 45-60 minutes per week in 15 minute blocks for the duration of the nine weeks of lessons. Recommended session practice time was of short duration, due to the potentially intense nature of the learning strategy that the intervention group would be following (McPherson \& Zimmerman, 2002). However, all participants were advised that the short duration was chosen due to "research suggesting that this was the optimal practice duration for novices".

At the first lesson, all participants were introduced to a practice diary on which they were encouraged to record the date, duration, general content, and their satisfaction with their independent practice sessions. Satisfaction with practice was included as this measure has been suggested to be a proxy measure for the application of self-regulation (Cleary \& Zimmerman, 2001; Kitsantas \& Zimmerman, 1998).

\subsubsection{Instructional Intervention}

All participants were informed they were to complete tasks as part of the study.

Intervention group: Participants in the intervention group initially discussed effective and less effective practice behaviours with the researchers. Subsequently, the purpose of the intervention was explained and participants were introduced to Zimmerman's (Cleary et al., 2006; Kitsantas \& Zimmerman, 1998; Zimmerman \& Kitsantas, 1996) three-step intervention strategy designed to enhance the quality of their practice. Step one required the participants to pick a specific element to work on for each five-minute block of practice (process goal): "What will you focus on improving?". At the conclusion of each five-minute block of practice, step two required the participants to self-record the extent to which they had achieved their process goal (self-reflection): "How did it go?". Step three asked participants to record what was responsible for any improvements in performance, or, where no improvement had been made, to suggest what they could do the next time they worked on that aspect (strategic attribution): "Why did it work?" or "What can you do to improve this?".

Placebo Group: After the baseline assessment, participants in the placebo group were briefed by the second researcher on their task. Four times each week, participants were asked to choose one new piece of music to listen to and to use a self-record form to detail what the piece of music was, when and where they listened to it, how much they enjoyed it, and to describe the piece of music in a few words. This activity was chosen so as to provide the participants with a task which required engagement and keeping a written log in a similar manner to the intervention group, while not encouraging self-regulatory practice behaviours. There were no restrictions placed on the placebo group, and if they did exhibit any self-regulated learning behaviours in their practice it was anticipated that this would be evidenced in the self-record sheets of their practice.

Self-record forms for the placebo and intervention groups were collected on a weekly basis in lessons. After the third week of the intervention, the second researcher returned to a music lesson to discuss the self-record forms and to provide feedback to the participants in both groups on how the forms were being completed (e.g., please remember to complete your forms and provide adequate details as initially instructed). 


\subsubsection{Final Assessment}

All participants were required to perform the same one-octave scale as in the baseline skills test, and a further two pieces. One piece was chosen by participants and could be anything that had been learned in the taught lessons, but the second piece was required to be Minuet no. 2 by J.S. Bach. This second piece was specifically chosen as a challenge, as it is in the ABRSM Grade 2 syllabus. In the first session, participants were informed that they were to learn this second piece completely independently, and would not be taught it during the lessons. The Bach was played to the participants by the instructor once in the first lesson and again in lesson six. It was anticipated that the learners would demonstrate strategic behaviours in the documentation of their independent learning of this work.

Prior to the final performance, participants completed the Self-efficacy for Musical Learning questionnaire. Subsequently, participants performed the scale, their chosen piece, and the independent study piece (Bach) to the researcher who had taught the lessons. Performances took place in a music practice room, and were video recorded for later analysis by the same independent assessor who rated the participant's initial performances, using the assessment criteria described above. The assessor was unaware of which participants were using the self-regulated learning worksheet during the study.

After the performance, participants completed a social validation questionnaire about their time in the study (Thelwell \& Greenlees, 2001). Specifically, the social validation questionnaire asked participants to respond on a scale from 1 (not at all) to 7 (extremely) to the questions: (1) How important is an improvement in performance to you? (2) Do you consider the changes in your performance to be significant? (3) How satisfied were you with the intervention? (4) Has the intervention proved useful to you? Finally, participants undertook a semi-structured interview. This interview allowed for additional information to be gathered regarding participants' self-reported practice behaviours, and their opinions of the intervention. The interviews were conducted by a research assistant who was naïve to which group the participants had belonged to. Participants were initially asked to describe a typical practice session. The next set of questions focused on eliciting descriptions of self-regulatory behaviour (e.g., "Is there anything that you do when you are practicing that you find particularly helpful? What do you do when you are practicing a particularly difficult section?). The final questions focused on participants' experiences of the intervention. Probes (e.g., Please tell me more about that?) were used to elicit additional information as required.

The overall design of the intervention is represented in the Treatment Fidelity Assessment Table (Table 1) below.

Table 1. Treatment Fidelity Assessment Table

\begin{tabular}{|c|c|c|}
\hline Type of fidelity & Steps taken to ensure fidelity & How was fidelity assessed? \\
\hline Fidelity to theory & $\begin{array}{l}\text { Intervention content consistent with } \\
\text { that designed in previous sporting } \\
\text { contexts } \\
\text { Intervention instruction exceeded that } \\
\text { used in previous investigations }\end{array}$ & Peer review of intervention design \\
\hline $\begin{array}{l}\text { Fidelity of provider } \\
\text { training }\end{array}$ & $\begin{array}{l}\text { Piloting of intervention with } \\
\text { volunteers, followed by peer debrief. }\end{array}$ & $\begin{array}{l}\text { A strict sequence of instruction was followed, and reviewed for } \\
\text { formal pilot study. }\end{array}$ \\
\hline $\begin{array}{l}\text { Fidelity of treatment } \\
\text { implementation }\end{array}$ & $\begin{array}{l}\text { A strict sequence of instruction } \\
\text { (curricular content and instructional } \\
\text { activities) was followed. } \\
\text { Regular meetings before delivery to } \\
\text { plan curriculum. }\end{array}$ & $\begin{array}{l}\text { Lessons were video recorded and a research assistant evaluated } \\
\text { random selections of lessons to ensure adherence to the sequence } \\
\text { of instruction and consistency between groups } \\
\text { Regular in-person observations of taught lessons. }\end{array}$ \\
\hline $\begin{array}{l}\text { Fidelity of treatment } \\
\text { receipt }\end{array}$ & $\begin{array}{l}\text { Review of participant worksheets and } \\
\text { practice diaries on a weekly basis } \\
\text { Feedback session after third week of } \\
\text { the intervention. }\end{array}$ & $\begin{array}{l}\text { Weekly checking/collection of diary/worksheet forms from } \\
\text { participants. } \\
\begin{array}{l}\text { Research assistant monitored discussions/collection } \\
\text { information. }\end{array}\end{array}$ \\
\hline $\begin{array}{l}\text { Fidelity of treatment } \\
\text { enactment }\end{array}$ & $\begin{array}{l}\text { Review of participant worksheets and } \\
\text { practice diaries to observe new skills } \\
\text { Interview with participants about } \\
\text { practice/learning experience }\end{array}$ & See results section \\
\hline
\end{tabular}

Table 1 presents a Treatment Fidelity Assessment that identifies the prerequisites for the intervention, how the processes were monitored, and how they were reviewed.

\subsubsection{Data Analysis}

Of the initial 22, thirteen participants (10 female, three male; four from the placebo group and nine from the intervention group) completed the final assessment and were included in the analysis. After the first month of lessons, over half of the placebo group had dropped out of the study, citing difficulty in achieving progress and frustration. Due to the small sample size of the placebo group, non-parametric statistics were used to compare the groups on the quantitative measures. Pearson's correlation coefficient $r$ provided a measure of effect size (Field, 2005). 
The practice diaries and the responses to the semi-structured interview questions from all participants who completed the study were deductively analysed for evidence of self-regulatory behaviours (McPherson \& Zimmerman, 2002). Both authors initially read both the practice diaries and the interview transcripts several times. Subsequently, the authors identified meaningful units of text in which self-regulatory behaviours were described. The two researchers then discussed their interpretation of the texts. Disagreements were discussed until consensus was reached (Sparkes, 1998). The same process was followed when analysing participants' evaluations of the interventions in the interview transcripts, however an inductive approach was followed.

\section{Results}

\subsection{Performance}

At the initial assessment, a Mann Whitney $U$ test revealed no significant difference between the groups on their performance of Twinkle Twinkle (Placebo: Median $=5, \mathrm{IQR}=0.75$; Intervention: Median $=6, \mathrm{IQR}=3$ ), $Z=-0.627, \mathrm{p}$ $=0.604, r=-0.17$. Due to variation in the difficulty of the participant-selected pieces, only performance of Minuet no. 2 was compared across groups. In the final assessment, there were again no differences between the groups on the assigned piece (Placebo: Median = 5, IQR = 1.13; Intervention: Median $=6, \mathrm{IQR}=4), Z=-0.469, \mathrm{p}=0.710, \mathrm{r}=-0.13$.

\subsection{Self-Efficacy for Learning}

At the initial assessment point, a Mann Whitney U test revealed that participants in the placebo group demonstrated significantly higher self-efficacy for learning (Median $=68.5, \mathrm{IQR}=9.75$ ) compared to the intervention group (Median $=56, \mathrm{IQR}=13.5), Z=2.006, \mathrm{p}=0.045, \mathrm{r}=0.55$. At the final assessment, no significant difference in self-efficacy for learning was reported between participants in the placebo group (Median $=64.5, \mathrm{IQR}=13.25$ ) compared to the intervention group (Median $=49, \mathrm{IQR}=21.75), Z=1.531, \mathrm{p}=0.126, \mathrm{r}=0.424$.

\subsection{Practice}

Participants were recommended to practice for a total of 15 minutes per session, four times per week (total 540 minutes). Adherence to these guidelines varied widely, from a low of 137 minutes, to a high of 1060 minutes across the eight weeks of the programme. The total amount of practice reported by participants in the placebo group (Median $=792.5$ minutes, $\mathrm{IQR}=450$ minutes) was considerably higher than that reported by the intervention group (Median $=290$ minutes, $\mathrm{IQR}=623$ minutes). While the $\mathrm{p}$-value for the comparison of practice duration was marginally greater than $0.05(Z=1.852, p=0.064, r=0.514)$, given the large effect size, and the fact that all participants in the placebo group exceeded the recommended 540 minutes total practice while five participants in the intervention group compiled total practice minutes of less than half of the recommendation, we can conclude that participants in the placebo group engaged in substantially more practice than participants in the intervention group.

\subsection{Self-Record Forms}

The self-record forms (self-regulation worksheet for the intervention group and the description of music listened to for the placebo group) showed that all participants adhered to their weekly tasks.

The diary entries by the intervention group revealed the implementation of a range of different self-regulatory behaviours. For example, participants reported structuring their practice sessions temporally (e.g., "having breaks helps") or environmentally (e.g., "played in front of mirror"). Participants also reported utilising a variety of strategies that they had noticed from within the taught lessons, such as part practice (e.g., "decided to write out all notes and break it down into small parts"), adopting a process focus (e.g., "concentrated on bowing and tried not to worry too much about sound"), and engaging in rehearsal (e.g., "tried to sing tune in my head"). In addition, a number of participants reported help seeking in response to persistent problems (e.g., "found a good resource on line").

Diary entries for the placebo group did not show evidence of specific self-regulated learning strategies. Instead, entries were non-descript, such as 'played the pieces'.

\subsection{Social Validation}

'An improvement in performance' was rated as important or very important by participants in both groups (Placebo, Median $=6.5, \mathrm{IQR}=1.5$; Intervention, Median $=5.5, \mathrm{IQR}=2$ ). Both groups considered 'the changes that had occurred within their playing' to be very significant (Placebo, Median $=6, \mathrm{IQR}=0.5$; Intervention, Median $=6, \mathrm{IQR}=1.25$ ). Both groups were very satisfied with 'the quality of the teaching that they received' (Placebo, Median = 7, IQR = 0; Intervention, Median $=6, \mathrm{IQR}=1$ ). In contrast to the positive opinion on the teaching provided and on their development as musicians, neither the self-regulation worksheet nor the placebo task was seen as particularly useful or not useful (Placebo, Median = 4.5, IQR = 1.75; Intervention, Median = 4.5, IQR = 2.25).

\subsection{Semi-Structured Interview}

When interviewed, all participants were asked to comment upon the intervention that they had experienced. Choosing 
and listening to pieces of music appeared to function effectively as a placebo activity as the participants engaged with the task: "Sometimes it was a bit hard to do if I didn't have the time, but I realised it would help me" (participant p4), "I thought it was really good. It was fun as well. Like, it seems kind of unrelated to what you are doing, then you realise that it's actually having an impact at the same time" (participant $\mathrm{p} 3$ ).

In terms of the self-regulation intervention, the majority of participants provided both negative and positive comments. Negative comments focused on the disruptive nature of the written task; e.g., "It would have been alright if it had been three parts, and I thought about it at the end of the week, but doing it all the time just seemed to break up my practice time too much and I would never get the momentum" (participant i4). Another participant viewed the task as a chore: "just more paperwork" (participant i1). Other participants described the intervention as "artificial" (participant i2) and "tedious" (participant i3). Participant i2 continued to explain:

"But that's [following the intervention's instructions to focus on specific elements] not what I really wanted to do and sometimes I would find it terribly frustrating and just play a few pieces...It frustrated my learning to be honest with you. I can see how that structure would be very useful for some people. Sometimes it did make me stop and think, but generally it made me stop and get annoyed."

Despite these negative comments, five of the participants in the intervention group specifically highlighted the benefit of the specific focus prompted by the self-regulation worksheet (e.g., "good for thinking about focus"; participant i4), and two participants also identified that using the three-step process encouraged reflective practice. For example, a male cellist reported "I thought it [the intervention] was really useful because it allowed me to reflect on what I was doing, and it also gave focus to a particular practice session as opposed to sitting down and just hitting the thing" (participant i8). In contrast, only one of the participants in the placebo group mentioned having a focus for their practice in their exit interview.

Participants were also asked to describe their typical practice behaviours. Only one participant reported implementing a specific routine when they practiced: "I would sit and go through the scales just to get my fingers nimble. Then I would play through initially the tunes we were learning. In the end, I would play through the pieces that we played today [the assessment pieces]" (participant p1). Irrespective of group, the remaining participants described practicing different elements, but without following any particular practice structure. One participant in the intervention group improved the efficiency of practice by eliminating the need to unpack the instrument, enabling short bursts of practice:

"When I practised, I left my violin out all the time, and I just picked it up all the time and I literally do 30 seconds or two minutes and put it down and come back to it five minutes later. So it was all there in my room and I picked it up all the time." (participant i4)

While discussing typical practice, a range of self-regulatory behaviours associated with effective practice were evidenced in the reports of the majority of the intervention group. These behaviours, matched those written in the practice diaries and on the self-regulated learning worksheet, included seeking help on Youtube ${ }^{\mathrm{TM}}$, utilising a mirror for feedback, setting specific proximal goals, and simplifying practice by slowing the pace of play or separating the piece into discrete segments. In contrast, the accounts of typical practice given by the placebo group participants provided much poorer evidence of self-regulatory behaviours with very few references to specific strategies beyond 'play it through'.

\section{Discussion}

This study investigated whether a self-regulation worksheet would encourage novice adult musicians to incorporate self-regulatory behaviours into their practice and whether, in turn, their higher quality of practice would enhance self-efficacy for learning, and subsequent performance. The analysis of the practice self-record sheets and exit interviews indicated that the intervention was successful in promoting self-regulatory behaviours. Participants within the intervention group made repeated reference to a range of self-regulatory processes. In contrast, participants from the placebo group made far fewer references to self-regulatory processes. Consequently, it appears that worksheets offer an effective means of promoting self-regulatory processes during independent practice.

Although the intervention appeared to be effective at promoting self-regulation, the worksheet had no impact on either performance attainment or self-efficacy for learning. One reason for this lack of effect may be the higher volume of practice completed by those participants from the placebo group who completed the study. Consistent with Hewitt (2011), although participants in the intervention group practiced less, there was no difference in attainment, suggesting that the practice completed by the intervention group to be more focused and effective.

An alternative reason for the limited impact of the intervention on achievement may be its mixed reception from participants. Many participants in the intervention group objected to the process of completing the self-regulation worksheet. Further consideration of how self-regulation instruction can be successfully integrated into teaching practices is warranted. Consistent with previous interventions in the sporting domain (Cleary et al., 2004) specific self-regulatory behaviours (goal setting, self-recording, self-attribution) were identified and prescribed for the learners at the outset of the intervention, but they were not given specific regimens of behaviours to use in their day-to-day practice, nor told exactly how to structure their 
practice. Within the lessons, techniques were explained and processes demonstrated, but there was no explicit instruction to repeat or transfer these processes in their practice. This choice was to ensure the teaching remained consistent across both groups, and was not an influencing factor in the research. The use of the worksheet was intended to bridge that gap with these adult learners. However, Zimmerman (1994) has argued that the development of self-regulatory skill may be enhanced when learners are allowed to exercise personal choice. Consequently, it may have been more appropriate to introduce the participants to a broader range of practice strategies (e.g., part practice, tempo regulation, etc) than those prescribed in the current study and guide participants to develop a set of processes most appropriate for themselves. In a future study this could be included with an extended 10 minutes at the end of the weekly lessons to specifically introduce self-regulated learning behaviours. In addition, it may be necessary to place greater emphasis on reinforcing and discussing the nature and purpose of the intervention with the participants on an on-going basis.

The requirement to complete the intervention worksheet may have been introduced too soon in the learning process (Singer, Flora, \& Abourezk, 1989; Tennant, Murray, \& Tennant, 2004). Asking participants to concentrate on both the novel instrument, and the specifics of their practice, may have overloaded the learners. Alternatively, Whitehead (1929/1967) described the earliest stage in learning as the "romance phase". In light of the comments provided by participants in the interviews, the introduction of a formal, disciplined approach to practice may be better suited to later in the learning process. Finally, Hallam (2001) suggested that knowledge of practice strategies is insufficient to enhance musical performance unless the student has developed the cognitive skill to be able to monitor and accurately evaluate performance. It is possible that the present study encouraged the use of strategies, particularly in terms of self-monitoring and recording, which these novice learners may not have been sufficiently skilled, instrumentally, to take on board (cf. Hewitt, 2011). Understanding how to use these strategies and having a suggested structure could potentially have saved those in the placebo group a great deal of time (see Miksza, 2011). Taking more time to reach a similar result suggests less efficiency, but also points to a sense of goal-directed behaviour and a desire to achieve. Learning in a social setting adds the possibility for a competitive desire to reach the end, and all participants were aware of the final performance goals.

There were a number of limitations to the present study. The use of self-regulatory behaviours was assessed indirectly, with practice quality interpreted from the diary and interview responses of participants. Future research should consider the direct assessment of learners at key points during the intervention (e.g., Duke et al., 2009; McPherson \& Renwick, 2001). A second limitation is the choice of an experimental design. Adherence to music practice is highly individual. Future research should consider whether alternative approaches, such as multiple-baseline single case research designs, and the inclusion of a variety of types of practice, as opposed to requiring the use of the worksheet in all practice sessions, would offer a more effective method of evaluating self-regulation interventions (Barker, McCarthy, Jones, \& Moran, 2011; Lidor \& Tenenbaum, 1994; Rogerson \& Hyrcaiko, 2002). Such an approach may also address the high drop-out rate experienced within the group design utilised in the present experiment.

In conclusion, the self-regulation worksheet encouraged these beginner adult instrumentalists to incorporate self-regulatory behaviours into their practice, however there was no direct benefit to their self-efficacy or learning. Considering both the content of interventions and the research designs used to evaluate effectiveness can enable more insight into the way self-regulation can be encouraged and enhance musical learning. The worksheet may prove a useful learning tool for musicians who are already familiar with technique on their instrument or when used with beginners alongside ongoing or monitored teacher-guidance. Future research should consider which strategies are most appropriate to introduce to learners at different time points in their development, and different methods of introducing these strategies to learners; a starting point in this line of research may be to explore the views of expert teachers (Varela, Abrami, \& Upitis, 2016).

\section{References}

Austin, J. R., \& Berg, M. H. (2006). Exploring music practice among sixth-grade band and orchestra students. Psychology of Music, 34, 535-558. https://doi.org/10.1177/0305735606067170

Barker, J., McCarthy, P., Jones, M., \& Moran, A. (2011). Single-case research methods in sport and exercise psychology. London: Routledge.

Bartolome, S. J. (2009). Naturally emerging self-regulated practice behaviors among highly successful beginning recorder students. Research Studies in Music Education, 31, 37-51. https://doi.org/10.1177/1321103X09103629

Bonneville-Roussy, A., \& Bouffard, T. (2015). When quantity is not enough: Disentangling the roles of practice time, self-regulation and deliberate practice in musical achievement. Psychology of Music, 43, 686-704. https://doi.org/10.1177/0305735614534910

Byo, J. L., \& Cassidy, J. W. (2008). An exploratory study of time use in the practice of music majors: Self-report and observation analysis. Update: Applications of Research in Music Education, 27, 33-40. https://doi.org/10.1177/8755123308322272

Christensen, S. E. (2010). Practicing strategically: The difference between knowledge and action in two eighth-grade 
students' independent instrumental practice. Update: Applications of Research in Music Education, 29, 22-32. https://doi.org/10.1177/8755123310377924

Cleary, T. J., \& Zimmerman, B. J. (2001). Self-regulation differences during athletic practice by experts, non-experts, and novices. Journal of Applied Sport Psychology, 13, 185-206. https://doi.org/10.1080/104132001753149883

Cleary, T. J., \& Zimmerman, B. J. (2004). Self-regulation empowerment program: A school-based program to enhance self-regulated and self-motivated cycles of student learning. Psychology in the Schools, 41, 537-550. https://doi.org/10.1002/pits.10177

Cleary, T. J., Zimmerman, B. J., \& Keating, T. (2006). Training physical education students to self-regulate during basketball free throw practice. Research Quarterly for Exercise and Sport, 77(2), 251-262. https://doi.org/10.1080/02701367.2006.10599358

Creswell, J., \& Plano, C. V. (2007). Designing and conducting mixed methods research. Thousand Oaks, CA: Sage.

Davidson, J. W., \& Jordan, N. (2007). 'Private teaching, private learning': An exploration of music instrument learning in the private studio, junior and senior conservatories. In L. Bresler (Ed.), International Handbook of Research in Arts Education (pp. 729-744). Dordrecht, The Netherlands: Springer. https://doi.org/10.1007/978-1-4020-3052-9_49

DiBenedetto, M. K., \& Zimmerman, B. J. (2010). Differences in self-regulatory processes among students studying science: A microanalytic investigation. The International Journal of Educational and Psychological Assessment, 5, $2-24$.

Dignath-van, E. C. (2011). Evaluating the effects of self-regulation trainings using meta-analysis. In B. J. Zimmerman \& D. H. Schunk (Eds.), Handbook of Self-Regulation of Learning and Performance (pp. 376- 392). New York, NY: Routledge.

Duke, R. A., Simmons, A. L., \& Davis, C. (2009). It's Not How Much; It's How: Characteristics of Practice Behavior and Retention of Performance Skills. Journal of Research in Music Education, 56, 310-321. https://doi.org/10.1177/0022429408328851

Ericsson, K. A., Krampe, R. T., \& Teschromer, C. (1993). The Role of Deliberate Practice in the Acquisition of Expert Performance. Psychological Review, 100, 363-406. https://doi.org/10.1037/0033-295X.100.3.363

Ertmer, P. A., \& Newby, T. J. (1993). Behaviorism, cognitivism, constructivism: Comparing critical features from an instructional design perspective. Performance Improvement Quarterly, 6, 50-72. https://doi.org/10.1111/j.1937-8327.1993.tb00605.x

Field, A. (2005). Discovering Statistics Using SPSS (2nd ed.). London: Sage Publications.

Fitzpatrick, K. R. (2011). A mixed methods portrait of urban instrumental music teaching. Journal of Research in Music Education, 59(3), 229-256. https://doi.org/10.1177/0022429411414912

Hallam, S. (2001). The development of expertise in young musicians: Strategy use, knowledge acquisition and individual diversity. Music Education Research, 3, 7-23. https://doi.org/10.1080/14613800020029914

Hewitt, M. P. (2011). The impact of self-evaluation instruction on student self-evaluation, music performance, and self-evaluation accuracy. Journal of Research in Music Education, 59, 6-20. https://doi.org/10.1177/0022429410391541

Jørgensen, H. (2000). Student learning in higher instrumental education: Who is responsible? British Journal of Music Education, 17, 67-77. https://doi.org/10.1017/S0265051700000164

Jørgensen, H. (2002). Instrumental performance expertise and amount of practice among instrumental students in a conservatoire. Music Education Research, 4, 105-119. https://doi.org/10.1080/14613800220119804

Kitsantas, A., \& Zimmerman, B. J. (1998). Self-regulation of motoric learning: A strategic cycle view. Journal of Applied Sport Psychology, 10, 220-239. https://doi.org/10.1080/10413209808406390

Kitsantas, A., \& Zimmerman, B. J. (2002). Comparing self-regulatory processes among novice, non-expert, and expert volleyball players: A microanalytic study. Journal of Applied Sport Psychology, 14, 91-105. https://doi.org/10.1080/10413209808406390

Kostka, M. J. (2002). Practice expectations and attitudes: A survey of college-level music teachers and students. Journal of Research in Music Education, 50, 145-154. https://doi.org/10.2307/3345818

Leon-Guerrero, A. (2008). Self-regulation strategies used by student musicians during music practice. Music Education Research, 10, 91-106. https://doi.org/10.1080/14613800701871439

Lidor, R., \& Tenenbaum, G. (1994). Applying learning strategy to a basketball shooting skill: A case study report. In R. Lidor, D. Ben-Sira, \& Z. Artzi (Eds.), Proceedings of the 1993 FIEP World Congress (pp. 53-59). Netanya, Israel: 
Wingate Institute.

McPherson, G. E., \& Renwick, J. M. (2001). A longitudinal study of self-regulation in children's musical practice. Music Education Research, 3, 169-186 https://doi.org/10.1080/14613800120089232

McPherson, G. E., \& Zimmerman, B. J. (2002). Self-regulation of musical learning: A social cognitive perspective. In R. Colwell \& C. Richardson (Eds.), The new handbook of research on music teaching and learning (pp. 327-347). Oxford: Oxford University Press.

Miksza, P. (2011). Relationships among achievement goal motivation, impulsivity, and the music practice of collegiate brass and woodwind players. Psychology of Music, 39(1), 50-67. https://doi.org/10.1177/0305735610361996

Miksza, P. (2012). The development of a measure of self-regulated practice behavior for beginning and intermediate instrumental music students. Journal of Research in Music Education, 59, 321-338. https://doi.org/10.1177/0022429411414717

Nielsen, S. (2001). Self-regulating learning strategies in instrumental music practice. Music Education Research, 3, 155-167. https://doi.org/10.1080/14613800120089223

Pitts, S., Davidson, J., \& McPherson, G. E. (2000). Developing effective practise strategies: Case studies of three young instrumentalists. Music Education Research, 2, 45-56. https://doi.org/10.1080/14613800050004422

Ritchie, L., \& Williamon, A. (2011). Measuring distinct types of musical self-efficacy. Psychology of Music, 38, 328344. https://doi.org/10.1177/0305735610374895

Rogerson, L. J., \& Hrycaiko, D. W. (2002). Enhancing competitive performance of ice hockey goaltenders using centering and self-talk. Journal of Applied Sport Psychology, 14, 14-26. https://doi.org/10.1080/10413200209339008

Rohwer, D., \& Polk, J. (2006). Practice behaviors of eighth-grade instrumental musicians. Journal of Research in Music Education, 54, 350-362. https://doi.org/10.1177/002242940605400407

Singer, R. N., Flora, L. A., \& Abourezk, T. L. (1989). The Effect of a Five-Step Cognitive Learning Strategy on the Acquisition of a Complex Motor Task. Journal of Applied Sport Psychology, 1, 98-108. https://doi.org/10.1080/10413208908406408

Tennant, L. K., Murray, N. P., \& Tennant, L. M. (2004). Effects of strategy use on acquisition of a motor task during various stages of learning. Perceptual and Motor Skills, 98(3 Pt 2), 1337-1344. https://doi.org/10.2466/pms.98.3c.1337-1344

Thelwell, R. C., \& Greenlees, I. A. (2001). The effects of a mental skills training package on gymnasium triathlon performance. The Sport Psychologist, 15, 127-141. https://doi.org/10.1123/tsp.15.2.127

Varela, W., Abrami, P. C., \& Upitis, R. (2016). Self-regulation and music learning: A systematic review. Psychology of Music, 44, 55-74. https://doi.org/10.1177/0305735614554639

Whitehead, A. N. (1967). The aims of education and other essays. New York: The Free Press. (Original work published 1929)

Zimmerman, B. J. (1994). Dimensions of academic self-regulation: A conceptual framework for education. In D. H. Schunk \& B. J. Zimmerman (Eds.), Self-regulation of learning and performance: Issues and educational approaches. Hillsdale, NJ: Lawrence Erlbaum Associates, Inc.

Zimmerman, B. J. (1998). Academic studying and the development of personal skill: A self-regulatory perspective. Educational Psychologist, 33, 73-86. https://doi.org/10.1080/00461520.1998.9653292

Zimmerman, B. J. (2002). Becoming a self-regulated learner: An overview. Theory into Practice, 41, 64-70. https://doi.org/10.1207/s15430421tip4102_2

Zimmerman, B. J., \& Kitsantas, A. (1996). Self-regulated learning of a motoric skill: The role of goal setting and self-monitoring. Journal of Applied Sport Psychology, 8, 60-75. https://doi.org/10.1080/10413209608406308

Zimmermann, K., \& Kitsantas, A. (1997). Developmental phases in self-regulation: Shifting from process goals to outcome goals. Journal of Educational Psychology, 89, 29-36. https://doi.org/10.1037/0022-0663.89.1.29

\section{Copyrights}

Copyright for this article is retained by the author(s), with first publication rights granted to the journal.

This is an open-access article distributed under the terms and conditions of the Creative Commons Attribution license which permits unrestricted use, distribution, and reproduction in any medium, provided the original work is properly cited. 